\title{
Study the Effect of Polycarbonate Superhydrophobic Nanocomposite on Antibacterial Activity
}

\author{
Muntadher Ismaiel Rahmah", Raad Saadon Sabry \\ Physics Department, College of Science, Al-Mustansiriyah University, Baghdad, Iraq \\ Email address: \\ superhydrophobicsurfaces@mail.ru(M. I. Rahmah) \\ ${ }^{*}$ Corresponding author
}

\section{To cite this article:}

Muntadher Ismaiel Rahmah, Raad Saadon Sabry. Study the Effect of Polycarbonate Superhydrophobic Nanocomposite on Antibacterial Activity. American Journal of Nanosciences. Vol. 4, No. 1, 2018, pp. 1-6. doi: 10.11648/j.ajn.20180401.11

Received: August 31, 2018; Accepted: September 25, 2018; Published: October 23, 2018

\begin{abstract}
A superhydrophobic and antibacterial surface on a glass substrate was fabricated by One-step phase separation method using the polycarbonate polymer and solvent $\backslash$ non- solvent. The resulting surfaces showed a static water contact angle (CA) of $154^{\circ}$ and excellent inhibition percentage of Pseudomonas aeruginosa bacteria. FESEM showed that the surface structure comprised branches or petals outside the "plant seabed's" formation, in addition to related AgNps and Ag with a rough structure. In order to test the stability, bacteria suspensions were poured above the surface and allowed to settle on top of the surface for several minutes, then, an Anti-adhesive effect of colonies bacteria evaluated with a very small percentage of bacteria adhesive on surfaces. This preparation method is advantageous as it does not require complicated or high-cost materials and is environmentally friendly and highly efficient.
\end{abstract}

Keywords: Pseudomonas Aeruginosa, AgNps, Ag, Acetone, Dmf, Superhydrophobic, Polycarbonate, Rough Structure

\section{Introduction}

In recent years, synthesis of nanoparticles (Nps) has special attention because of increased surface area to volume ratio, increased activity, and modified structure compared to macromolecules [1]. Nps are added to polymers to obtain unique physical and chemical properties, which cannot be achieved, by adding particles with micronized, silver nanoparticles (AgNps) are reported to exhibit the strong biocidal effect on more species of bacteria including Pseudomonas aeruginosa bacteria [2]. Hence increasing their contact with bacteria, vastly improve their bactericidal effectiveness. They bind to microbial DNA, preventing bacterial replication, and to sulfhydryl groups in the metabolic enzymes of the bacterial electron transport chain, causing their inactivation [3, 4]. PCs are an important thermoplastic polymer because of low-cost, inexpensive, non-toxic, and temperature resistant and exhibits low water absorption properties [5]. Therefore, PCs are very attractive material using in a wide range of applications includes medical devices, bulletproof windows, food packaging, mineral water bottles, packaging and self-cleaning [6].
Moreover, they dissolve easily in organic solvents (like DCM, DMF, and THF) and exhibits low water CA $\left(\sim 84^{\circ}\right)$ with hydrophilic properties [7]. According to Cassie's Model [8], when surface roughness or surface hydrophobicity increases, it becomes unlikely for water and completely follows the surface topography of a hydrophobic substrate. Moreover, if the water has a complete contact with a solid surface, a system is in a high-energy state. On the other hand, if the water has partial contact with a solid, it is more energetically favorable; then, air may be trapped between the surface texture and water. It is sometimes also referred to as the 'fakir state' because the drop sits on a bed of micro nails. The apparent CA of an air/liquid/solid interface is the sum of all contributions of different phase fractions. The minimum interfacial energy, together with Young's relation applied to a solid surface, then result to Cassie-Baxter relation:

$$
\operatorname{Cos} \theta_{c}=f_{1} \cos \theta_{1}+f_{2} \cos \theta_{2}
$$

Here $\theta_{c}$ is CA, $\theta_{1}$ and $\theta_{2}$ are the CAs on two different types of materials; $f_{1}$ and $f_{2}$ are the surface fraction of two materials. If the liquid rest fully on air, the contact angle would be $180^{\circ}$ : the smaller $f_{\text {solid }}$, the closer to this extreme situation, and the higher contact angle. For air $\cos \left(180^{\circ}\right)=-$ 
1 , and $f_{2}=\left(1-f_{1}\right)$, therefor (Eq.1) can be rewritten as [9]:

$$
\operatorname{Cos} \theta_{c}=f_{1}(1+\cos \theta-1)
$$

Here $\theta$ is $\mathrm{CA}$ on a flat surface, $f_{1}$ is solid-liquid fractions under the contact area, This implies to achieve CA, the contribution from solid phase must be small as possible and this equation shows that high aspect ratio of pillars. Nps dispersed in PC polymer is called polymer nanocomposite and it is considered as a single the homogeneous material, these materials exhibit unique mechanical, thermal and biological properties when compared to conventional composites [10, 11]. The extent of modification of the property depends on the size, distribution, base polymer and dispersion of the Nps and on the adhesion at the filler-matrix interface [12]. In the present study, we selected low-cost technique for fabricating PC surface with a rough surface structure in one-step, without a need for low surface energy material modification and special instruments by using solvent/non-solvent selected method. Also, comparing and study the effect of surface energy, $\mathrm{AgNps}$, and $\mathrm{Ag}$ on inhibition percentage of Pseudomonas aeruginosa bacteria.

\section{Experimental}

\subsection{Materials}

PC resin bought from Sabic Saudia. Acetone (C3H6O; purity of 99\%) from Himedi India and DMF (C3H7NO; purity of $99.9 \%$ ) from Scharlau Spain. Silver sheet from J. M chemicals limited (purity of 99\%), and Silver microparticles from Anala-R (purity of 99\%). A glass substrate acquired from Yingke Optical Products.

\subsection{Substrate Preparation}

A glass slides used as substrates, were cleaning with ethanol and ultrasonic bath for $15 \mathrm{~min}$, then with distilled water in order to remove the residuals and impurities such as some of oxides and grease from the surface, after that surface dried carefully by hot air and with soft paper.

\subsection{Preparation of AgNps}

Synthesis of AgNps with an average particle size (30 nm) carried out by Q-switched Nd: YAG pulses laser source with following experimental conditions: 9 ns pulses, $532 \mathrm{~nm} 6 \mathrm{~Hz}$ repetition rate, and a constant energy at $400 \mathrm{~mJ}$ per pulse. The beam laser focused using a lens with a focal length of $250 \mathrm{~mm}$ to achieve sufficient laser intensity to create a spark in the Ag target. The target is immersing in a quartz beaker contain DMF solvent (20 mL DMF solvent level above Ag target was kept at $3 \mathrm{~mm}$ ). After some time of action laser beam on Ag target, the solution of surfactant becomes colored. To make AgNps generation process more efficient, a laser beam scanning the target surface completely. DMF AgNps solution stirred during ablation with a magnetic stirrer for $0.5 \mathrm{~h}$. After a stirrer, a small amount of colored solution extracted for absorption measurement by UV-Vis absorption spectroscopy equipped with a xenon lamp and a wavelength range $(300-900 \mathrm{~nm})$ to measurement average particle size.

\subsection{Preparation of PC Nanocomposite}

In a typical synthesis, $\mathrm{PC}$ resin dissolved in acetone/DMF mixture at a concentration of $2 \%(\mathrm{~g} / \mathrm{ml})$ with ultrasonically dispersed for $15 \mathrm{~min}$ and magnetically stirred for $1 \mathrm{~h}$. Then, AgNps added carefully to PC solution at $0.001,0.002$ and $0.003 \%(\mathrm{~g} / \mathrm{ml})$ and $\mathrm{Ag}$ at $8.2(\mathrm{~g} / \mathrm{ml})$ with magnetically stirred for $6 \mathrm{~h}$. After homogeneity, $1 \mathrm{ml}$ of the solution was drop cast on a clean glass substrate using a micropipette (from Global Huawei). Then solution evaporated in room temperature.

\subsection{Antibacterial Activity Evaluation}

The Anti-bacterial effect of PC surface against pathogenic Pseudomonas aeruginosa bacteria (Obtained from Department of biology/ college of science / Al- Mustansiriya University / Baghdad / Iraq). PC surface was coated on glass. After drying, the bacterial suspensions $\left(10^{8} \mathrm{cell} / \mathrm{ml}\right)$ are poured into the Surface and allowed to settle on the top of Surfaces. The control plates contained bacterial suspensions only without coated. Both coated and controlled plates incubated at $37^{\circ} \mathrm{C}$ for $24 \mathrm{~h}$. After the incubation $1 \mathrm{ml}$ of each dilution taken and spread on nutrient agar (Hi-Media) and then incubated at $37^{\circ} \mathrm{C}$ for $24 \mathrm{~h}$. The colonies count and inhibition effect is evaluated, and then calculate percent reduction of the bacterial growth. The Anti-adhesive effect was determined by projecting experiment that explained in anti-bacterial effect. After incubated for $24 \mathrm{~h}$ of control plates and coated, unattached bacterial cells are removed by washing plates, three times with water, then drying at room temperature for $15 \mathrm{~min}$. After the drying crystal violet (1\%) added to plates for $20 \mathrm{~min}$. The stained attached bacterial cells are rinsed three times with distilled water. Allowed to dry at room temperature for $15 \mathrm{~min}$ and extracted twice $95 \%$ ethanol, then the absorbance measured at $590(\mathrm{~nm})$ using a spectrophotometer.

\subsection{Characterization}

The surface morphology of Specimens observed with FESEM. The wettability behavior and water CA measured by the homemade instrument at ambient temperature, as shown in Figure 1, and this process was monitored by a high-speed CCD camera with a setting of 25 frames per second. The optical properties are examined use UV-Vis absorption spectroscopy. Biological features investigated by spectrophotometer and micro plate readers. 


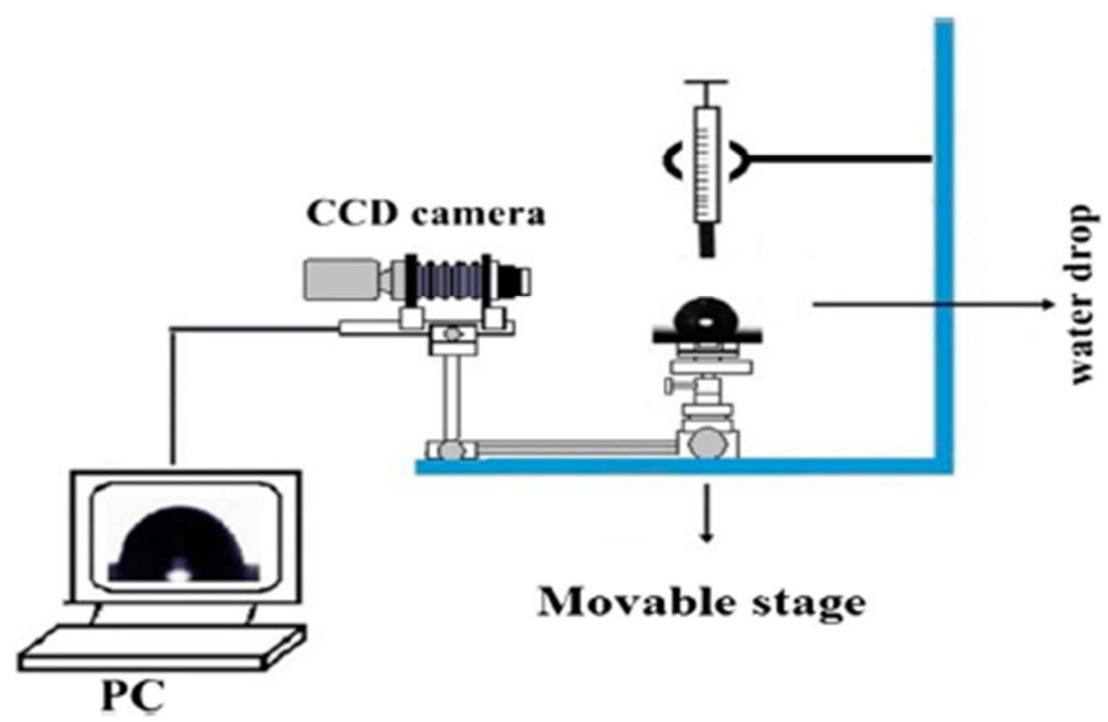

Figure 1. Experimental setup to measure water $C A$.

\section{Results and Discussion}

PC surface has been fabricated using solvent/non-solvent selected method by treatment with DMF and acetone solvents, also $\mathrm{Ag}$ and $\mathrm{AgNps}$ was added to the PC pure solution. Gram-negative Pseudomonas aeruginosa is common and has rod-shaped which cause a disease to the animals, plants, and humans. In addition, antibiotic resistance is associated with the serious illnesses such as pneumonia, Urinary tract infection, Septic shock, soft and Skin tissue infections [15]. Figure 2 Shows FESEM image morphology PC after adding $0.001(\mathrm{~g} / \mathrm{ml})$ of AgNps. From this results, the surface does not have enough roughness with show a porous network, because acetone/DMF mixture percentage is $20 \%$, therefore, the surface energy of PC surface is high, with a strong adhesion of bacteria on surfaces. At the same time, when AgNps added the percentage of inhibition
Pseudomonas aeruginosa bacteria is $50 \%$, due to their ability to influence on bacteria. Figure 3, A and 3, B are FESEM images of PC surface prepared by adding $68 \%$ of acetone/DMF solvents with 0.002 and $0.003(\mathrm{~g} / \mathrm{ml})$ of AgNps. From these figures, results show that PC surface has roughly structured comprised branches or petals outside the 'plant seabeds' formation, with stabilizes of AgNps on branches or petals of PC structured. The percentage inhibition of Pseudomonas aeruginosa bacteria was $60 \%$ and $85 \%$ respectively, with very low adhesive percentage of bacteria on surfaces. Due to homogeneous distribution to AgNps on branches or petals of roughly structured and acetone/DMF mixture percentage increased which leads to decrease surfaces energy of PC surfaces. Therefore, an adhesive percentage of bacteria decreases with the roughly structured increase [16].

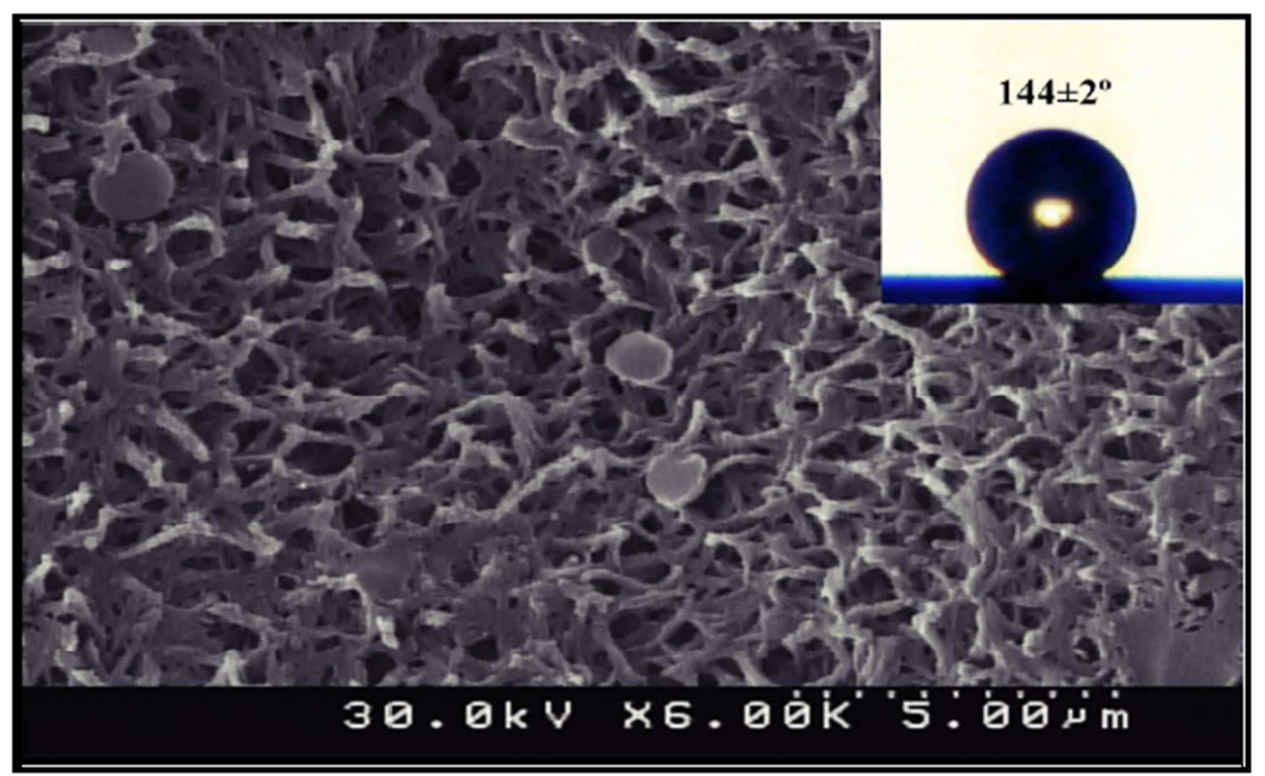

Figure 2. FESEM images of PC surface formed after treatment with acetone/DMF mixture of 20\% and added 0.001 (g/ml) of AgNps. Inset is CA on a surface. 

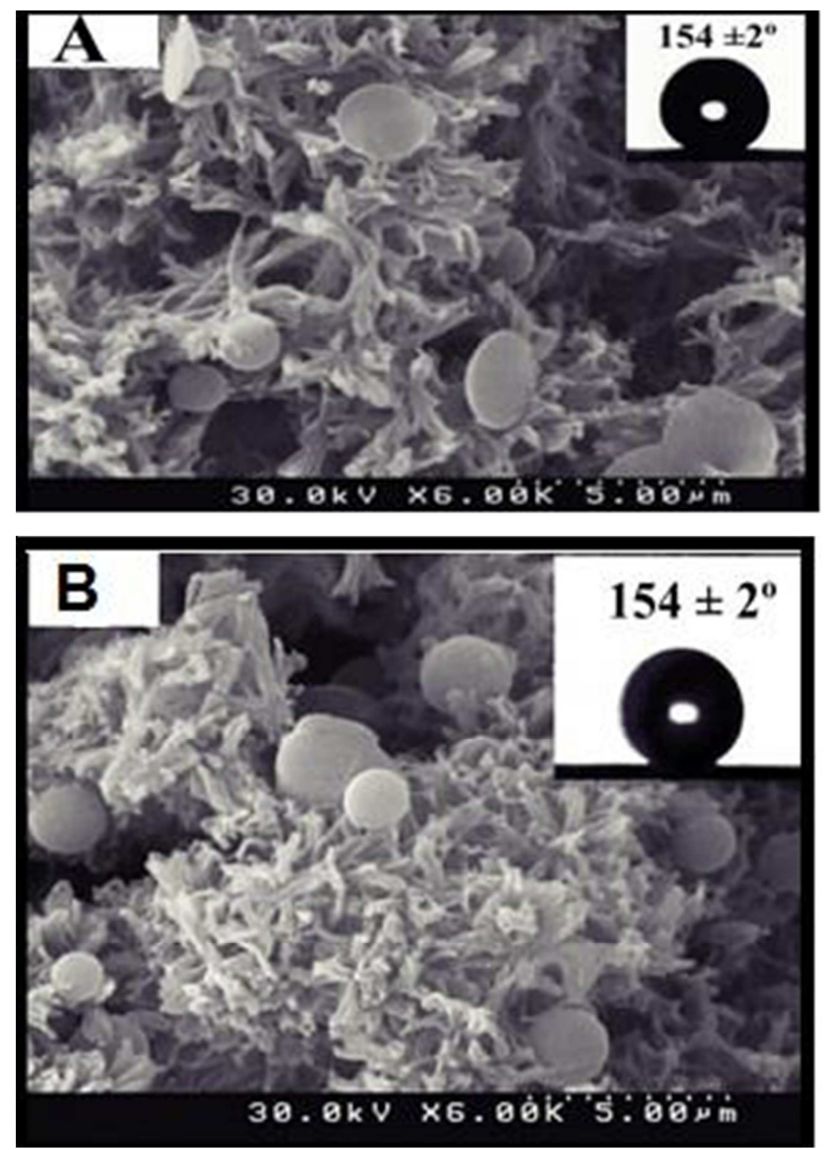

Figure 3. FESEM images of PC surfaces formed after adding (A) $0.002 \%$ and (B) $0.003(\mathrm{~g} / \mathrm{ml})$ of AgNps, respectively. And added $0.002(\mathrm{~g} / \mathrm{ml})$ of AgNps. Insets are CA for each surface.

Figure 4 illustrates the effect of PC surface against pathogenic Pseudomonas aeruginosa bacteria on the nutrient agar, which contains bacteria.

To explain experimental results, AgNps are an extremely small size and a large surface to volume ratio, which leads to both physical and chemical properties differences in compared to the Ag of the same chemical composition, such as biological, catalytic activity, thermal properties. Therefore, AgNps stabilized on the petals or branches of "plants seabed" structure of PC surface play an important role in killing or inhibition of bacteria and the creation of disease-resistant environment through mixing it with other materials such as PC polymer, because of the aspect ratio (surface/volume) that leads the contacts with the surface of the bacteria to be increasing. Anti-bacterial mechanisms of AgNps action on bacteria clarify briefly in Figure 5 AgNps attachment to the cell wall of bacteria and caused accumulation of the envelope protein precursors lead to immediate dissipation of proton motive force. Therefore, AgNps can interact with a base of DNA (phosphate groups and sulfur-containing) and effect on DNA ability to replicate. Moreover, AgNps exhibit destabilizes in rupture of the plasma membrane and outer membrane, causing depletion of ATP. Also, AgNps can penetrate the cell membrane through attach to the cell membrane surface and inhibiting the cell respiration. The cations AgNps bind with thiol groups of bacterial proteins and leading to cell death [17]. Acetone/DMF solvent mixture played an important role in the formation of roughly structured of the surface. DMF has a solubility in water with a high melting point of up to $154^{\circ} \mathrm{C}$ and absolute solubility in the PC polymer. Thus, the evaporation of the solvent required more time to complete. Meanwhile, acetone is soluble in water, with a low boiling point $\left(57^{\circ} \mathrm{C}\right)$ and partial solubility in the PC polymer. Then, the evaporation of the solvent required a few time to complete. Therefore, a difference in the speed of evaporation and the rate of solubility for PC of two solvents, and leads to an effect on the morphology of the resulting surface, then caused the formation of the rough structure and decrease a surfaces energy of PC surfaces.
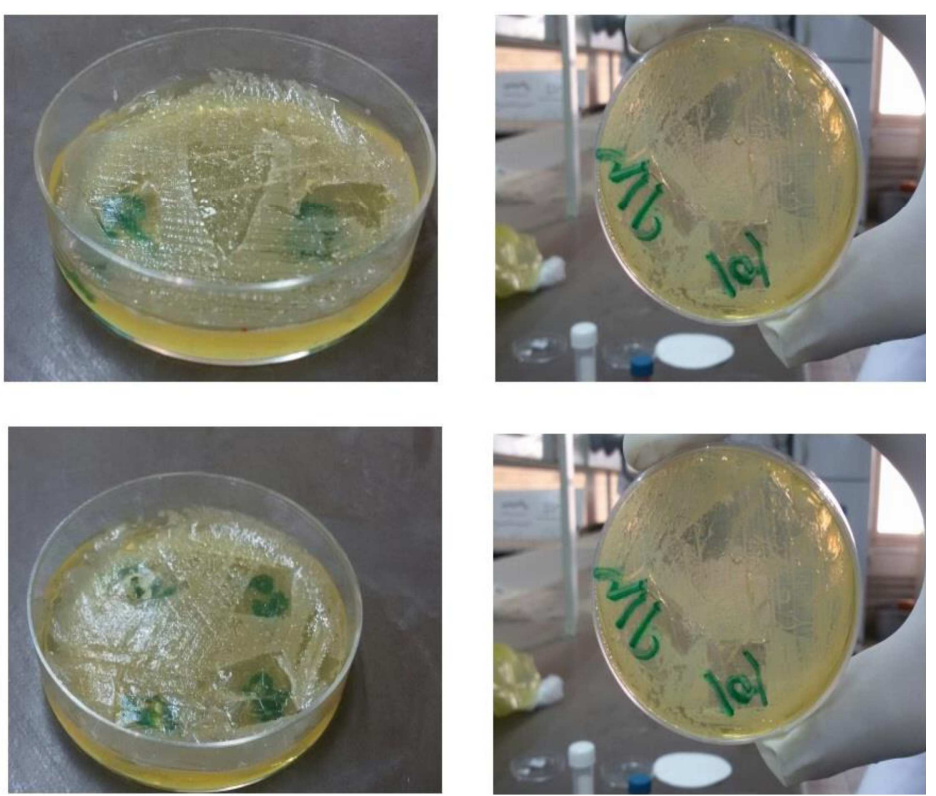

Figure 4. Zones inhibition of PC surface. 
For Comparison between the effect of $\mathrm{AgNps}$ and $\mathrm{Ag}$ on the percentage inhibition of bacteria, $8.2(\mathrm{~g} / \mathrm{ml})$ of $\mathrm{Ag}$ was adding to PC solution. Figure 6 Illustrates the FESEM images of PC surface rough surface prepared by adding $68 \%$ of acetone/DMF solvents with $8.2(\mathrm{~g} / \mathrm{ml})$ of Ag. The percentage inhibition of Pseudomonas aeruginosa bacteria was $50 \%$, with a very low adhesive percentage. However, these results obtained after adding a very large amount of $\mathrm{Ag}$, while, best results obtained by using very few amounts of AgNps, Therefore, using AgNps instead of Ag become very important in economic and commercial fields.

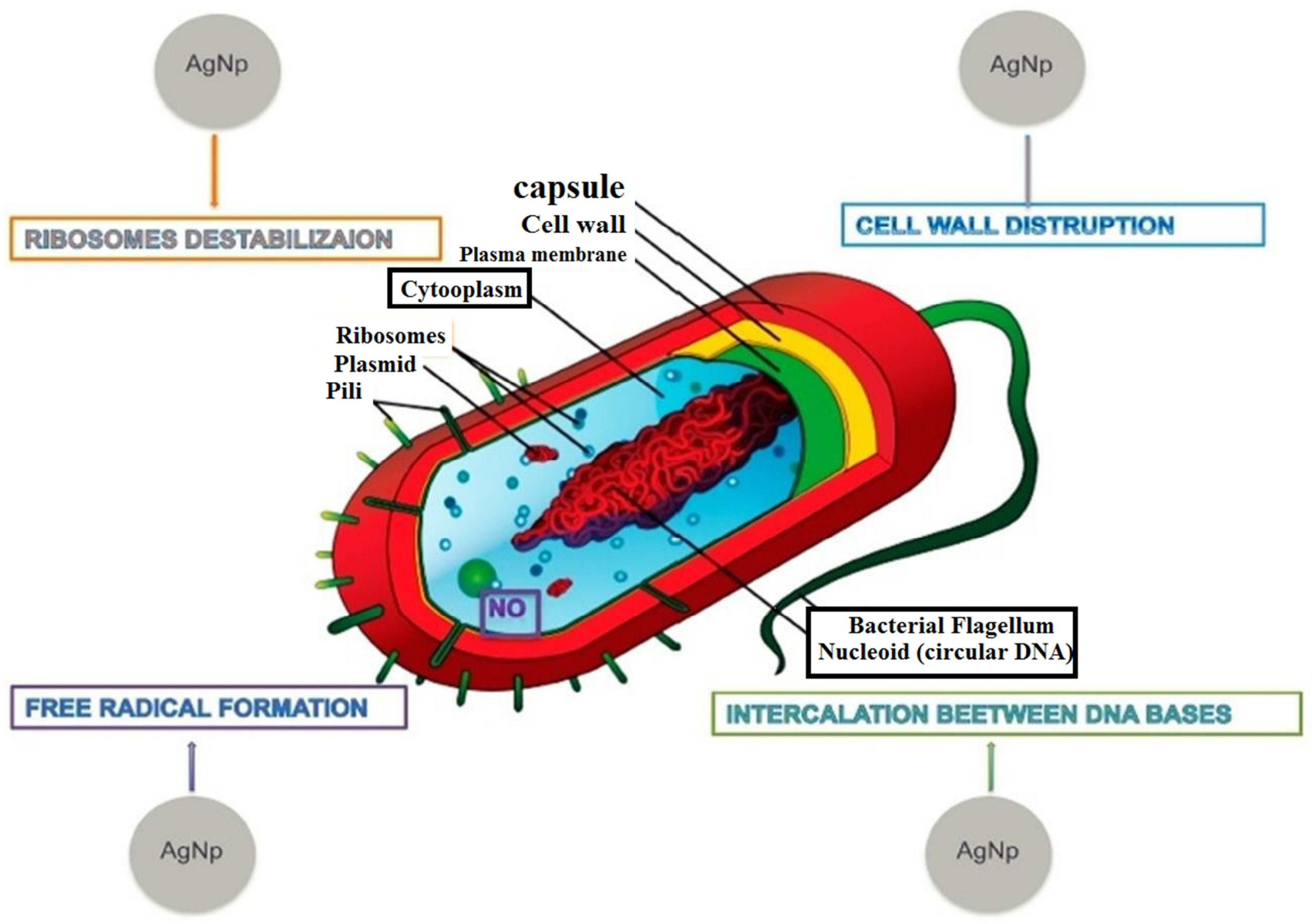

Figure 5. Summarize mechanisms of AgNps action [16].

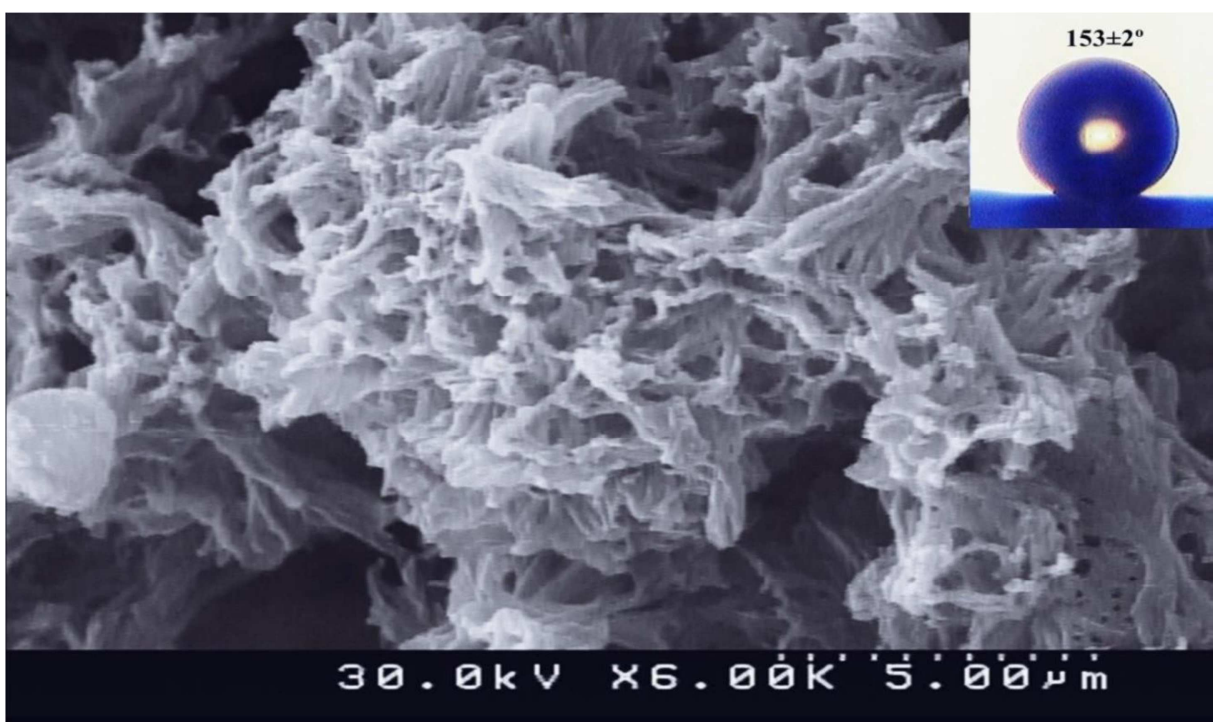

Figure 6. FESEM image of PC surface formed after treatments with acetone/DMF mixture and adding $8.2 \%(\mathrm{~g} / \mathrm{ml})$ of $\mathrm{Ag}$. Inset is CA on surface. 
In order to evaluate the stability of PC surfaces in the ambient environment, Pseudomonas aeruginosa suspensions poured onto a surface and allowed to settle on top it for several minutes, then suspensions drop roll to a surface. After incubation $1 \mathrm{ml}$ of each dilution at $37^{\circ} \mathrm{C}$ for $24 \mathrm{~h}$, the Antiadhesive effect of colonies bacteria is recognizing and the results showed a very small percentage of bacteria was adhesive on the surface. In addition, CAs measured for each condition and observe very little change in CA. Besides that, wettability of surface is stable in ambient environment.

\section{Conclusions}

A stable PC surfaces have been obtained directly without addition of low-surface-energy materials by a solvent/nonsolvent selected method. AgNps and rough structure play an important role in the inhibition of bacteria and the creation of a disease-resistant environment, because of the aspect ratio that contact with the surface of bacteria increasing, so the growth of Pseudomonas aeruginosa bacteria decrease. Antibacterial activity showed that the inhibition and adhesive percentage of bacteria increase with a percentage of AgNps and solvent/non-solvent increase. In order to a comparison between an effect of AgNps and Ag, the result showed excellent inhibition percentage obtained by using very few amounts of $\mathrm{AgNps}$, in comparison with use a very a large amount of $\mathrm{Ag}$, Therefore, using $\mathrm{AgNps}$ instead of $\mathrm{Ag}$ become very important in economic and commercial fields. This method is very suitable apply to other polymers to fabricate Superhydrophobic surface with Antibacterial Activity.

\section{Acknowledgements}

This author is grateful for the financial support received for this work from (Department of physics/ college of science / Al-Mustansiriya University / Baghdad / Iraq).

\section{References}

[1] Bardajee, G. R., Hooshyar, Z., Rezanezhad, H., A novel and green biomaterial based silver nanocomposite hydrogel: synthesis, characterization and antibacterial effect. J. Inorg. Biochem., 2012; 117:367-373.

[2] Yeo SY, Jeong SH, Preparation and characterization of polypropylene/ silver nanocomposite fibers. Polymer International, 2003; 52: 1053-1057.

[3] Maki DG, Tambyah PA, Engineering Out the Risk of Infection with Urinary Catheters. Emerging Infectious Diseases, 2001; 7: $342-347$.

[4] Lansdown AB, Silver L., Its antibacterial properties and mechanism of action. Journal of Wound Care, 2002; 11: 125130
[5] Delpech MC, Coutinho FMB, Habibe MES. Bisphenol Abased polycarbonates: characterization of commercial samples. Polymer Test. 2002; 21(2):155-161.

[6] Balart R, Sánchez L, López J, et al. Kinetic analysis of thermal degradation of recycled polycarbonate/acrylonitrilebutadiene-styrene mixtures from waste electric and electronic equipment. Polym Degrad Stab. 2006; 91(3):527-534.

[7] Schulz U. Review of modern techniques to generate antireflective properties on thermoplastic polymers. Appl Opt. 2006; 45(7):1608-1618.

[8] Cassie ABD, Baxter S. Wettability of porous surfaces. Trans Faraday Soc. 1944; 40:546-551.

[9] Wolfs M, Darmanin T, Guittard F. Superhydrophobic fibrous polymers. Polym Rev. 2013; 53(3):460-505.

[10] Honary S, Ghajar K, Khazaeli P, et al. Preparation, characterization and antibacterial properties of silver-chitosan nanocomposites using different molecular weight grades of chitosan. Trop J Pharm Res. 2011; 10(1):69-74.

[11] Li S-M, Jia N, Zhu J-F, et al. Rapid microwave-assisted preparation and characterization of cellulose silver nanocomposites. Carbohydr Polym. 2011; 83(2):422-429.

[12] Prucek R, Tuček J, Kilianová $M$, et al. The targeted antibacterial and antifungal properties of magnetic nanocomposite of iron oxide and silver nanoparticles. Biomaterials. 2011; 32(21):4704- 4713.

[13] P. Jankowski, D. Ogonczyk, A. Kosinski, W. Lisowski, P. Garstecki, "Hydrophobic modification of polycarbonate for reproducible and stable formation of biocompatible microparticles", Lab Chip, 2011; 11:748-752.

[14] Vividha Dhapte, Namrata Gaikwad, Priyesh V. More, Shaibal Banerjee, Vishwas V. Dhapte, Shivajirao Kadam \& Pawan K. Khanna, Transparent $\mathrm{ZnO} /$ polycarbonate nanocomposite for food packaging application, Nanocomposites, 2015; 1(2):106112 .

[15] Mathee K, Narasimhan G, Valdes C, Qiu X, Matewish JM, Koehrsen M, Rokas A, Yandava CN, Engels R, Zeng E, Olavarietta R, Doud M, Smith RS, Montgomery P, White JR, Godfrey PA, Kodira C, Birren B, Galagan JE, Lory S, "Dynamics of Pseudomonas aeruginosa genome evolution", Proc. Natl. Acad. Sci. U.S.A. (2008).

[16] Loo CY, Young PM, Lee WH, Cavaliere R, Whitchurch CB, and Rohanizadeh R. Loo CY, "Superhydrophobic, nanotextured polyvinyl chloride films for delaying Pseudomonas aeruginosa attachment to intubation tubes and medical plastics", Acta Biomater., 2012; 8(5):1881-90.

[17] Gianluigi Franci, Annarita Falanga, Stefania Galdiero, Luciana Palomba, Mahendra Rai, Giancarlo Morelli and Massimiliano Galdiero, "Silver Nanoparticles as Potential Antibacterial Agents", Molecules, 2015; 20: 8856-8874. 